\title{
Optimizing CPAP Treatment for Obstructive Sleep Apnea
}

\author{
Robert Hiensch $^{1}$ • Desh S. Nandedkar ${ }^{1} \cdot$ Steven H. Feinsilver ${ }^{1}$
}

Published online: 23 April 2016

(C) Springer International Publishing AG 2016

\begin{abstract}
Obstructive sleep apnea is a common chronic illness, for which positive airway pressure remains the best treatment. Optimizing patient adherence to this treatment is often challenging. Controversies remain regarding the optimal strategy for initiating treatment, and whether the choice of specific positive airway pressure modality is important. Increasingly, treatment may be started using an auto-titrating machine without in-laboratory titration. Recent advances in technology permit monitoring of patient compliance and efficacy, but have not proven to necessarily improve outcomes.
\end{abstract}

Keywords Obstructive sleep apnea $\cdot$ Positive airway pressure $\cdot$ Auto-titrating machine $\cdot$ Continuous positive airway pressure $\cdot$ Sleep disorders

\section{Introduction}

Obstructive sleep apnea (OSA) is a condition characterized by repeated upper airway obstruction during sleep and has been associated with hypertension, motor vehicle accidents, neurocognitive impairment, and cardiovascular disease [1]. The prevalence of this disease is similar to that for other major chronic illnesses such as diabetes or asthma. Continuous positive airway pressure (CPAP) is the primary form of treatment

This article is part of the Topical Collection on Sleep Related Breathing Disorders

Steven H. Feinsilver

Steven.feinsilver@mssm.edu

1 Center for Sleep Medicine, Division of Pulmonary, Critical Care and Sleep Medicine, Icahn School of Medicine at Mount Sinai, 1 Gustave Levy Place, Box 1232, New York, NY 10029, USA for symptomatic, moderate, and severe disease, and is rapidly effective in abolishing sleep-disordered breathing and minimizing its symptoms [2]. However, adherence with this therapy is in many ways more challenging than for other chronic disease treatments. This paper will review strategies to optimize CPAP treatment for obstructive sleep apnea.

\section{Defining Adherence}

Although the Centers for Medicare and Medicaid Services considers patients with CPAP use $>4$ h per night on $>70 \%$ of nights "adherent," the health benefits are linearly related to hours of CPAP use [3, 4], with those using CPAP greater than $6 \mathrm{~h}$ per night normalizing daytime sleepiness measures [2]. Despite its high efficacy, however, CPAP is not always well tolerated and long-term adherence can be low, limiting its effectiveness. The data estimating CPAP compliance is hard to evaluate, but is generally disappointing. In an older paper, nearly $30 \%$ of patients prescribed CPAP refuse therapy from the onset, and another $25 \%$ discontinue therapy during the first year [5]. In the SAVE trial, which did not include patients with severe sleepiness, compliance with CPAP for at least $4 \mathrm{~h}$ per night was $39 \%$ at 1 year [1]. Evaluation of adherence to CPAP treatment for sleep apnea may appear to be excessively poor because of how common and easy it is to monitor its usage; for example, it is not routine to objectively measure adherence to inhaled therapy for airways disease, but this has been estimated at 22 to $78 \%$ in various studies [6].

\section{Risks for Lower Adherence}

Early recognition of patients at risk for noncompliance or resistance to treatment is important to allow for targeted 
interventions aimed at improving adherence. Consistently identifying individual patient factors that predict noncompliance, however, has proven difficult. No single demographic, such as sex, age, race, or marital status reliably predicts adherence, although some studies have suggested that lower socioeconomic status is associated with reduced CPAP use, accounting for cost of therapy [7], a phenomenon that CPAP shares with many other non-OSA related therapies. Certain medical conditions can make CPAP adherence inherently difficult, including stroke, in which OSA is particularly common [8] and sinus disease [9]. A history of depression, anxiety, and claustrophobia are other comorbid conditions that have been found to predict poor adherence, and may be amenable to intervention [10]. Physiologic factors such as increasing apnea-hypopnea index (AHI), body measurement index (BMI), and sleepiness weakly but consistently correlate to increased CPAP adherence, although the perceived and objective benefits of therapy may be more important $[11,12]$. With a host of conflicting and inconsistent studies, researchers have attempted to aggregate the most important elements into a practical clinical calculator. The Index for Nonadherence to PAP (I-NAP) therapy was $87 \%$ sensitive and $63 \%$ specific in a largely white population in identifying non-adherers, but these questionnaires require further validation in different clinical settings [13].

Although it is generally accepted that long-term adherence to CPAP correlates to adherence early in the course of therapy [14], in a recent study of patients with minimal symptoms, usage at 2-4 weeks correlated moderately with usage at 6 months, but a significant minority with low usage early were successful at 6 months follow-up [15]. In this study, only male gender was associated with long-term use, not severity of apnea or symptoms.

\section{Initiating Treatment}

The early pattern of use is critical and interventions in the first three days of treatment, and even factors related to initial testing and PAP exposure, may predict long-term adherence [1, 16]. Therefore, factors that may affect the testing experience are of great interest as these can actively influence the future chances of success. The value of early, clear communication and education between provider and patient cannot be underestimated, and sleep consultation by a sleep specialist prior to diagnostic polysomnography (PSG) has been shown to increase use of CPAP by $1 \mathrm{~h}$ per night [17]. The importance of a proactive, rather than a reactive, approach to identifying potential non-adherers is demonstrated by studies that show that cognitive behavioral therapy prior to PAP titration improves long-term adherence and clinical outcomes [18, 19] but not when performed after 1 week of therapy [20]. Early spousal and social support and initial problems with CPAP further modify long-term adherence [10, 21].
Because of the importance of early experiences on longterm adherence patterns, the use of hypnotics has been studied as a way to improve adherence both as a single dose during titration in the laboratory and to improve sleep in the first few weeks of treatment. Results are mixed. Adherence was improved in one single night study using eszopiclone for CPAP titration [22], but not in another study using zaleplon during a split night titration [23]. Longer term, use of zolpidem for 2 weeks did not improve CPAP compliance in one study [24], but eszopiclone during titration testing and in the first 2 weeks of therapy was associated with greater adherence and less discontinuation as far as 6 months out [25]. These studies suggest at least that hypnotics may be useful in some patients for initiating therapy. Their use does not appear to negatively impact testing accuracy or treatment, and in fact a 2015 Cochrane Database review found no evidence that sedating medications worsen obstructive sleep apnea [26].

\section{Split Night Testing, Automatic Titration, and Home Testing}

Additional components of adherence and the testing experience that are relevant to consider include the impact of split night studies, automatic titrating machines, and home testing. A retrospective analysis of 400 patients at Walter Reed Army Medical Center with full night or split night CPAP titration showed no difference in CPAP adherence at 4-6 weeks of follow-up [27]. A study of 98 veterans compared in-lab titration to auto CPAP for treatment initiation [28]. Adherence as measured by both hours per night and number of nights used was better in the group that had in-lab titration. Randomized clinical trials to answer these questions are lacking.

Home testing is becoming increasingly common. This is most useful for patients with a high pretest probability for moderate to severe OSA without significant comorbid conditions [29]. Rosen et al. in the Home-PAP multicenter open labeled trial compared standard in-lab polysomnography and CPAP titration to home sleep study followed by auto-titrating CPAP therapy [30]. Treatment outcomes were mostly equal in 3 month follow-up, with slightly increased CPAP use in the home group. The authors noted that $31 \%$ of subjects with AHI $<15$ on home testing were found to have AHI $>15$ on lab testing. This previously known lower sensitivity for home sleep testing may eliminate some of the cost savings for this diagnostic strategy.

\section{Establishing Treatment}

Once the decision to prescribe PAP therapy has been made, the prescriber must consider the technical factors that may influence long-term success. Heated humidification seems to 
increase adherence, perhaps by reducing nasopharyngeal side effects [31], although treatment of rhinitis with nasal steroids does not increase PAP therapy adherence in an unselected patient population [32, 33]. Patient input on interface selection and fitting is needed to reduce leakage, minimize abrasion, and increase comfort. Nasal-pillow styles are generally considered more comfortable and have fewer side effects, and in one study was shown to increase adherence [34,35], although this has not been consistently replicated. The use of full-face masks has been shown to require higher therapeutic pressures compared to nasal or nasal-pillow masks, which may also have an impact on patient tolerance and compliance [36] Changing from a nasal mask to a full-face mask once treatment has started without adjusting treatment pressures may lead to a higher residual apnea-hypopnea index, and decreased therapeutic benefit [37]. It is not unusual to try several mask types or sizes before finding an appropriate interface. In patients who are reporting high amounts of mouth leak, use of a chin strap may help with reducing leak and mouth dryness, and has been associated with improved short term compliance and efficacy [38].

Specific PAP modes have an uncertain effect on adherence. Bilevel PAP (BPAP), in which a separately adjustable lower expiratory PAP (EPAP) and higher inspiratory PAP (IPAP) is prescribed, does not increase adherence [39], although Ballard et al. were able to identify a subgroup population who were able to increase their adherence by switching to a form of BPAP with reduced late inspiratory and early expiratory pressures when CPAP was not tolerated [40]. Auto-titrating PAP devices (APAP) have an emerging role in the treatment of OSA, but their effect on long-term adherence is slight [41]. Expiratory pressure relief, in which a pressure dip at the beginning of exhalation allows for lessened back pressure, increases comfort and is preferred by patients, but, in studies, has not consistently led to increased adherence [42].

\section{Monitoring Treatment}

Once treatment has been established, prompt follow-up of patients will be required to evaluate any barriers to continued use, as well as to ascertain efficacy of PAP treatment. Multiple trials have shown benefit to aggressive patient education and follow-up within the first month as a means of increasing PAP compliance. Interventions which have shown benefit include printed materials and weekly phone calls [43] home education including partner education, home visits by a trained sleep nurse, and multi-night PAP titration studies [44]. Follow-up in the office should occur at the very least between 30 and 90 days after initiation of PAP therapy to comply with CMS guidelines. Follow-up even earlier (at 3-7 days) may be reasonable given the impact the first week of use have on longterm adherence.
A frequent issue is the ability of treated patients to perform potentially hazardous tasks such as driving or operating machinery. There is good evidence that the increased risk of motor vehicle accidents is reduced to a level indistinguishable from ordinary drivers with adequate CPAP use. A study by George of Canadian driving records for patients for the 3 years prior and 3 years after diagnosis and treatment showed a threefold higher incidence of accidents before treatment, and no difference from the general population after treatment [45]. The time course of improvement with CPAP treatment as measured by driving simulator performance may be as rapid as several days of treatment [46], although a recent study suggests residual impairment even with long-term adequate treatment [47]. Generally, patients with documented adherence of at least $4 \mathrm{~h}$ per night for $70 \%$ of nights are cleared to return to driving. Current recommendations for commercial motor vehicle operation are summarized in a recent review [48].

Even in the most highly motivated patients, CPAP usage is never $100 \%$ because of factors including travel, social issues, and illness. In a study by Kohler et al., patients on CPAP for at least 1 year had recurrence of sleep apnea as measured by oxygen desaturation index within 4 nights [49]. In a more recent study, 42 subjects on CPAP with good adherence for 2-3 months had CPAP discontinued for 2 nights. Indices of sleep-disordered breathing returned to pretreatment levels but with less severe oxygen desaturations and a tendency to shift from apneas to hypopneas [50] Patients with severe apnea should accordingly be informed that even brief interruptions of therapy may have consequences.

\section{Long-Term Disease Management}

Long-term management requires that patients realize that they have a chronic disease likely requiring lifelong treatment. Treatment plans must be individualized, but at a minimum, once comfortably compliant on CPAP documented to be efficacious, we advise patients being treated to see a sleep physician annually in addition to routine care by their primary care provider. Patients should be given written instructions for the care and cleaning of their equipment. Table 1 shows the suggested replacement intervals for equipment from one manufacturer. The ability of newer pressure generators to measure efficacy in addition to compliance allows objective measures to be considered, and likely obviates the need for repeat polysomnography in most patients. Treatment may need to be adjusted for significant changes in weight or after surgery involving the upper airway. Our general algorithm for followup of patients on PAP is shown in Fig. 1.

During follow-up visits, subjective and objective assessments can be made of the patient to assess response 
Table 1 Recommended replacement intervals for PAP equipment

\begin{tabular}{ll}
\hline Nasal cushion and nasal pillows & 15 days \\
Full-face cushions & 30 days \\
Headgear & 6 months \\
Disposable filter & 1 month \\
Tubing & 3 months \\
Humidifier chamber & 6 months \\
CPAP device & $5-7$ years
\end{tabular}

Resmed http://www.resmed.com/us/en/consumer/support/replacement/ replacement-option.html

to therapy. Efficacy data should also be assessed at this time. Many PAP machines have the capability to measure respiratory events through proprietary algorithms analyzing the flow signal of the PAP machine. This comes with the inherent limitation of all data being extrapolated solely from changes in the flow signal. While detection of apneas is generally felt to be accurate, hypopnea evaluation is more limited without oxygen desaturation or electro-cortical arousal data. Additionally, manufacturers will have different algorithms for evaluation of events, so inter-device comparisons can be difficult. Mask leak is another factor which can affect detection of respiratory events, as well as having a direct impact on adherence. Again, each manufacturer has different algorithms and criteria for detecting high leak. There is limited data on the overall accuracy of PAP machine efficacy monitoring, but a consensus statement by the ATS suggests that "Very high or low values for residual apneas/hypopneas or mask leak appear to be clinically useful in chronically managing patients with sleep apnea" [51].

Fig. 1 Outline of PAP follow-up

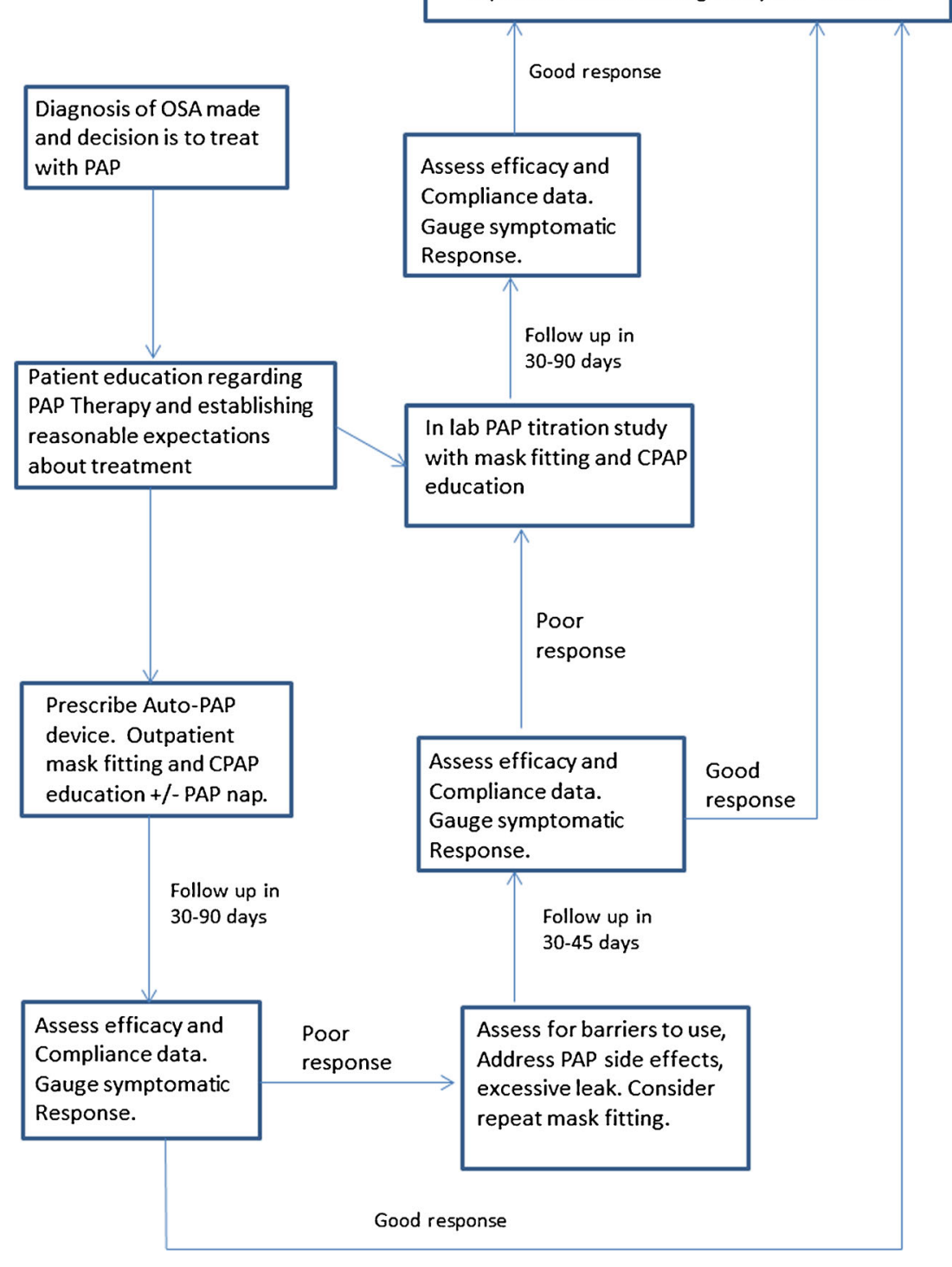

Follow up 6 months, then yearly if stable. Replace mask and tubing every 3-6 months. 


\section{Conclusion}

Obstructive sleep apnea is a common, chronic disease for which the best treatment remains CPAP at this time. Uncertainty exists regarding the optimal diagnostic and treatment strategy with the availability of home sleep studies and auto-titrating machines. We believe that treatment should be individualized, with either in-lab titration or auto-titration at home as reasonable approaches depending on patient wishes and availability. Adherence to therapy is key, and only a few days of treatment withdrawal may lead to significant impairment. It is unclear whether any PAP treatment modality is superior in improving patient comfort or adherence. Newer CPAP equipment allows adherence and efficacy to be routinely measured, which it is hoped will lead to better outcomes.

\section{Compliance with Ethical Standards}

Conflict of Interest Robert Hiensch, Desh S. Nandedkar, and Steven $\mathrm{H}$. Feinsilver declare that they have no conflict of interest.

Human and Animal Rights and Informed Consent This article does not contain any studies with human or animal subjects performed by any of the authors.

\section{References}

1. Chai-Coetzer CL, Luo YM, Antic NA, Zhang XL, Chen BY, $\mathrm{He} \mathrm{QY}$, et al. Predictors of long-term adherence to continuous positive airway pressure therapy in patients with obstructive sleep apnea and cardiovascular disease in the SAVE study. Sleep. 2013;36(12):1929-37.

2. Weaver TE, Grunstein RR. Adherence to continuous positive airway pressure therapy: the challenge to effective treatment. Proc Am Thorac Soc. 2008;5(2):173-8.

3. Stradling JR, Davies RJ. Is more NCPAP better? Sleep. 2000;23 Suppl 4:S150-3

4. Zimmerman ME, Arnedt JT, Stanchina M, Millman RP, Aloia MS. Normalization of memory performance and positive airway pressure adherence in memory-impaired patients with obstructive sleep apnea. Chest. 2006;130(6):1772-8.

5. McArdle N, Devereux G, Heidarnejad H, Engleman HM, Mackay TW, Douglas NJ. Long-term use of CPAP therapy for sleep apnea/hypopnea syndrome. Am J Respir Crit Care Med. 1999;159(4 Pt 1):1108-14.

6. Makela MJ, Backer V, Hedegaard M, Larsson K. Adherence to inhaled therapies, health outcomes and costs in patients with asthma and COPD. Respir Med. 2013;107:1481-90.

7. Campbell A, Neill A, Lory R. Ethnicity and socioeconomic status predict initial continuous positive airway pressure compliance in New Zealand adults with obstructive sleep apnoea. Intern Med J. 2012;42(6):e95-101.

8. Palombini L, Guilleminault C. Stroke and treatment with nasal CPAP. Eur J Neurol. 2006.

9. Sugiura T, Noda A, Nakata S, Yasuda Y, Soga T, Miyata S, et al. Influence of nasal resistance on initial acceptance of continuous positive airway pressure in treatment for obstructive sleep apnea syndrome. Respiration. 2007;74(1):56-60.

10. Lewis KE, Seale L, Bartle IE, Watkins AJ, Ebden P. Early predictors of CPAP use for the treatment of obstructive sleep apnea. Sleep. 2004;27(1):134-8.

11. Olsen S, Smith S, Oei T, Douglas J. Health belief model predicts adherence to CPAP before experience with CPAP. Eur Respir J. 2008;32(3):710-7.

12. Drake CL, Day R, Hudgel D, Stefadu Y, Parks M, Syron ML, et al. Sleep during titration predicts continuous positive airway pressure compliance. Sleep. 2003;26(3):308-11.

13. Sawyer AM, King TS, Hanlon A, Richards KC, Sweer L, Rizzo A, et al. Risk assessment for CPAP nonadherence in adults with newly diagnosed obstructive sleep apnea: preliminary testing of the Index for Nonadherence to PAP (I-NAP). Sleep Breath. 2014;18(4):875-83.

14. Budhiraja R, Parthasarathy S, Drake CL, Roth T, Sharief I, Budhiraja P, et al. Early CPAP use identifies subsequent adherence to CPAP therapy. Sleep. 2007;30(3):320-4.

15. Turnbull CD, Bratton DJ, Craig SE, Kohler M, Stradling JR. In patients with minimally symptomatic OSA can baseline characteristics and early patterns of CPAP usage predict those who are likely to be longer-term users of CPAP. J Thorac Dis. 2016;8(2):276-81.

16. Stepnowsky CJ, Dimsdale JE. Dose-response relationship between CPAP compliance and measures of sleep apnea severity. Sleep Med. 2002;3(4):329-34.

17. Pamidi S, Knutson KL, Ghods F, Mokhlesi B. The impact of sleep consultation prior to a diagnostic polysomnogram on continuous positive airway pressure adherence. Chest. 2012;141(1):51-7.

18. Richards D, Bartlett DJ, Wong K, Malouff J, Grunstein RR. Increased adherence to CPAP with a group cognitive behavioral treatment intervention: a randomized trial. Sleep. 2007;30(5):635-40.

19. Olsen S, Smith SS, Oei TP, Douglas J. Motivational interviewing (MINT) improves continuous positive airway pressure (CPAP) acceptance and adherence: a randomized controlled trial. J Consult Clin Psychol. 2012;80(1):151-63.

20. Aloia MS, Smith K, Arnedt JT, Millman RP, Stanchina M, Carlisle $\mathrm{C}$, et al. Brief behavioral therapies reduce early positive airway pressure discontinuation rates in sleep apnea syndrome: preliminary findings. Behav Sleep Med. 2007;5(2):89-104.

21. Baron KG, Smith TW, Berg CA, Czajkowski LA, Gunn H, Jones CR. Spousal involvement in CPAP adherence among patients with obstructive sleep apnea. Sleep Breath. 2011;15(3):525-34.

22. Lettieri CJ, Collen JF, Eliasson AH, Qyast TM. Sedative use during continuous positive airway pressure titration improves subsequent compliance: a randomized, placebo-controlled trial. Chest. 2009; 136:1263-8.

23. Park JG, Olson EJ, Morgenthaler TI. Impact of zaleplon on continuous positive airway pressure therapy compliance. J Clin Sleep Med. 2013;9:439.

24. Bradshaw DA, Ruff GA, Murphy DP. An oral hypnotic does not improve continuous positive pressure airway pressure compliance in men with obstructive sleep apnea. Chest. 2006;130:1369.

25. Lettieri CJ, Sah AA, Holley AB, Kelly WF, Chang AS, Roop SA. Effects of a short course of eszopiclone on continuous positive airway pressure adherence: a randomized trial. Ann Intern Med. 2009;151:696-702.

26. Mason M, Cates CJ, Smith I. Effects of opioid, hypnotic and sedating medications on sleep-disordered breathing in adults with obstructive sleep apnoea. Cochrane Database Syst Rev. 2015;7: CD011090.

27. Collen J, Holley A, Lettieri C, Shah A, Roop S. The impact of splitnight versus traditional sleep studies on CPAP compliance. Sleep Breath. 2010;14(2):93-9.

28. Means MK, Edinger JD, Husain AM. CPAP compliance in sleep apnea patients with and without laboratory CPAP titration. Sleep Breath. 2004;8(1):7-14. 
29. Collop NA, Anderson WM, Boehlecke B, Claman D, Goldberg R, Gottlieb DJ, et al. Clinical guidelines for the use of unattended portable monitors in the diagnosis of obstructive sleep apnea in adult patients. Portable Monitoring Task Force of the American Academy of Sleep Medicine. J Clin Sleep Med. 2007;3(7):737-47.

30. Rosen CL, Auckley D, Benca R, Foldvary-Schaefer N, Iber C, Kapur V, et al. A multisite randomized trial of portable sleep studies and positive airway pressure autotitration versus laboratory-based polysomnography for the diagnosis and treatment of obstructive sleep apnea: The HomePAP Study. Sleep. 2012;35(6):757-67.

31. Massie CA, Hart RW, Peralez K, Richards GN. Effects of humidification on nasal symptoms and compliance in sleep apnea patients using continuous positive airway pressure. Chest. 1999;116(2):403-8.

32. Strobel W, Schlageter M, Andersson M, Miedinger D, Chhajed PN, Tamm M, et al. Topical nasal steroid treatment does not improve CPAP compliance in unselected patients with OSAS. Respir Med. 2011;105(2):310-5.

33. Ryan S, Doherty LS, Nolan GM, McNicholas WT. Effects of heated humidification and topical steroids on compliance, nasal symptoms, and quality of life in patients with obstructive sleep apnea syndrome using nasal continuous positive airway pressure. J Clin Sleep Med. 2009;5(5):422-7.

34. Mortimore IL, Whittle AT, Douglas NJ. Comparison of nose and face mask CPAP therapy for sleep apnoea. Thorax. 1998;53(4):290-2.

35. Beecroft J, Zanon S, Lukic D, Hanly P. Oral continuous positive airway pressure for sleep apnea: effectiveness, patient preference, and adherence. Chest. 2003;124(6):2200-8.

36. Ebben MR, Oyegbile T, Pollak CP. The efficacy of three different mask styles on a PAP titration night. Sleep Med. 2012;13(6):645-9.

37. Ebben MR, Narizhnaya M, Segal AZ, Barone D, Krieger AC. A randomised controlled trial on the effect of mask choice on residual respiratory events with continuous positive airway pressure treatment. Sleep Med. 2014;15(6):619-24.

38. Knowles SR, O'Brien DT, Zhang S, Devara A, Rowley JA. Effect of addition of chin strap on PAP compliance, nightly duration of use, and other factors. J Clin Sleep Med. 2014;10(4):377-83.

39. Smith I, Lasserson TJ. Pressure modification for improving usage of continuous positive airway pressure machines in adults with obstructive sleep apnoea. Cochrane Database Syst Rev. 2009.

40. Ballard RD, Gay PC, Strollo PJ. Interventions to improve compliance in sleep apnea patients previously non-compliant with continuous positive airway pressure. J Clin Sleep Med. 2007;3(7):706-12.

41. Ip S, D'Ambrosio C, Patel K, Obadan N, Kitsios GD, Chung M, et al. Auto-titrating versus fixed continuous positive airway pressure for the treatment of obstructive sleep apnea: a systematic review with meta-analyses. Syst Rev. 2012;1:20.

42. Aloia MS, Stanchina M, Arnedt JT, Malhotra A, Millman RP. Treatment adherence and outcomes in flexible vs standard continuous positive airway pressure therapy. Chest. 2005;127(6):2085-93.

43. Chervin RD, Theut S, Bassetti C, Aldrich MS. Compliance with nasal CPAP can be improved by simple interventions. Sleep. 1997;20(4):284-9.

44. Hoy CL, Vennelle M, Kingshott RN, Engleman HM, Douglas NJ. Can intensive support improve continuous positive airway pressure use in patients with the sleep apnea/hypopnea syndrome? Am J Respir Crit Care Med. 1999;159(4):1096-100.

45. George CF. Reduction in motor vehicle collisions following treatment of sleep apnoea with nasal CPAP. Thorax. 2001;56:508-12.

46. Turkington P, Sircar M, Saralaya D, Elliott M. Time course of changes in driving simulator performance with and without treatment in patients with sleep apnoea hypopnoea syndrome. Thorax. 2004;59(1):56-9.

47. Vakulin A, Baulk SD, Catcheside PG, et al. Driving simulator performance remains impaired in patients with severe OSA after CPAP treatment. J Clin Sleep Med. 2011;7:246-53.

48. Colvin LJ, Collop NA. Commercial motor vehicle driver obstructive sleep apnea screening and treatment in the United States: an update and recommendation overview. J Clin Sleep Med. 2016;12(1):113-25.

49. Kohler M, Stoewhas AC, Ayers L, et al. The effects of CPAP therapy withdrawal in patients with obstructive sleep apnea: a randomized controlled trial. Am J Respir Crit Care Med. 2011;184:1192-9.

50. Young LR, Taxin ZH, Norman RG, Walsleban JA, Rapaport DM, Ayappa I. Response to CPAP withdrawal in patients with mild versus severe obstructive sleep apnea/hypopnea syndrome. Sleep. 2013;36(3):405-12.

51. Schwab RJ, Badr SM, Epstein LJ, Gay PC, Gozal D, Kohler M, et al. An official American thoracic society statement: continuous positive airway pressure adherence tracking systems. The optimal monitoring strategies and outcome measures in adults. Am J Respir Crit Care Med. 2013;188(5):613-20. 